(RESEARCH ARTICLE)

\title{
The effect of calabash chalk on the uterus of adult female Wistar rats
}

\author{
Opara Julia K. * and Nwagbaraocha Eileen C. \\ Department of Anatomy, college of Medicine and Health Sciences, Gregory University, Uturu, Abia State, Nigeria.
}

Publication history: Received on 30 September 2018; revised on 13 October 2018; accepted on 19 October 2018

Article DOI: https://doi.org/10.30574/gscbps.2018.5.2.0109

\begin{abstract}
The study investigated the effect of calabash chalk on the uterus of adult female Wistar rats. The 15 female adult Wistar rats were randomly divided into groups A, B and C. Group A served as the control while groups B and C served as experimental groups. Their body weights were measured on a weekly basis throughout the experimental period. In addition to feed and water given to all groups, group A received distilled water only for 21 days, group B $40 \mathrm{mg} / \mathrm{kg}$ per body weight of non-salted calabash chalk for 21 days and group C $40 \mathrm{mg} / \mathrm{kg}$ per body weight of salted calabash chalk for 21 days. On the 22nd day the animals were sacrificed and their uterus harvested for histological studies. Data was analysed using one-way ANOVA and SPSS version 2.0. The body weight of animals in group B was significantly reduced $(\mathrm{P}<0.05)$ when compared to control group. The histological findings of the uterus revealed endometrial hyperplasia and presence of inflammatory cells in the group treated with non-salted calabash chalk and epithelial metaplasia coupled with endometrial hyperplasia in the group treated with salted calabash chalk. These hyperplastic and metaplastic effect could be attributed to the presence of lead in calabash chalk. Calabash chalk could cause histological changes in the uterus. Thus, prolonged or regular consumption of calabash chalk should be discouraged as it has been shown to have negative effect.
\end{abstract}

Keywords: Calabash chalk; Uterus; Histology; Wistar rats

\section{Introduction}

Calabash chalk is a type of geophagic material that is traditionally consumed by people (especially pregnant women) as a remedy to morning sickness, nausea and for pleasure [1]. It is also used as facial powder and as an antiperspirant when grounded [2]. Calabash chalk comes in a variety of forms such as powders, moulded shapes and blocks. It exists as two types; salted and non-salted. Calabash chalk is also known as calabar stone; in Nigeria it is known as Nzu by the Ibos, Ndom by the Efik/Ibibios and Ulo in some parts of Bini [3]. In addition it is also known as La Craie or Argile in French, Shilè in Ghana and Mabele by the Lingala speaking people of Congo [4].

The practice of eating earth, including soil and chalk is known as Geophagia [5]. Geophagia is practiced for various reasons including religious beliefs, medicinal purposes, or as part of a regular diet [6]. It is a common practice in Nigeria and some sub-Saharan African countries. According to Abrahams [7], when geophagic materials come in contact with the digestive fluids they have the potential of releasing clinical or sub-clinical toxic effects on the individual.

Calabash chalk majorly constitutes aluminium silicate hydroxide $\left(\mathrm{Al}_{2} \mathrm{Si}_{2} \mathrm{O}_{5}(\mathrm{OH})_{4}\right)$ which comes from the kaolin clay group, making $\mathrm{Al}_{2} \mathrm{Si}_{2} \mathrm{O}_{5}(\mathrm{OH})_{4}$ a standard formula for calabash chalk [8]. Calabash chalk also consists of metalloids and metals like lead; which forms a high percentage of its constituent, arsenic, iron, aluminium, potassium, zinc, titanium, manganese, barium, chromium, copper, nickel, rubidium and tin respectively [9].

\footnotetext{
${ }^{*}$ Corresponding author

E-mail address: oparajulia@gmail.com
} 
The concentration of lead in calabash chalk has been reported to be approximately $40 \mathrm{mg} / \mathrm{kg}$ which is higher than the approved dietary concentration [4,10]. Exposure to higher levels of lead can cause problems in pregnancy as well as learning and behavioural problems in young children $[11,12]$. Previous reports have shown that calabash chalk causes ovarian follicle atresia, vacuolation and necrosis [13], fragmentation of the liver parenchymal cells and dilatation of hepatic sinusoids [14], demineralization of the femur bone and alteration in growth rate [15]. Further research also showed calabash chalk to cause enlargement of the spleen [16], oedema and haemorrhage in the stomach mucosa, koilocytic and hyperkeratosis changes in the mucosa of the oesophagus [8]. Based on this background that this research was carried out so as to ascertain the effect this chalk has on the uterus which serves as the conduit for reproduction.

\section{Material and methods}

\subsection{Experimental animals}

A total of 15 adult female Wistar rats weighing between 190 and $250 \mathrm{~g}$ were procured and bred from/in the animal house of the Department of Anatomy, Gregory University, Uturu. They were fed with feed and water ad libitum and were allowed to acclimatize for a period of two weeks before commencement of treatment. Ethical approval was sort and approved by the ethical committee of the College for animal care and use, Gregory University, Uturu which is in compliance with the National regulation for animal research.

\subsection{Preparation and administration of the solution}

Two forms of calabash chalks (salted and unsalted) were crushed into powdered form and $2 \mathrm{~g}$ of each powder was dissolved in $200 \mathrm{ml}$ of distilled water giving a concentration of $10 \mathrm{mg} / \mathrm{ml}$. It was then filtered with filter paper to remove debris in the solution. $40 \mathrm{mg} / \mathrm{kg}$ body weight equivalent of the chalk solution was administered to the experimental animals using an oral cannula. The solution was administered once daily between the hours of 10 am - 2.30 pm for a period of 21 days.

\subsection{Experimental protocol}

The fifteen adult female Wistar rats were randomly divided into 3 groups of five animals each, designated as groups A, $B$ and C. Group A served as the control group and received distilled water only, Group B received $40 \mathrm{mg} / \mathrm{kg}$ body weight of Non-salted calabash chalk daily for 21 days and Group C received $40 \mathrm{mg} / \mathrm{kg}$ body weight of Salted calabash chalk daily for 21 days. After the twenty first day, the animals from various groups were weighed and their weight recorded. Twenty four hours after last administration the animals were anaesthetized by chloroform inhalation and dissected through the abdominopelvic region. The uterus was harvested and fixed in $10 \%$ formal saline for histological examination.

\subsection{Histopathological analysis}

The uterus from the control and treated animals were fixed in $10 \%$ formal saline. The tissues were processed by passing them through ascending grades of alcohol. It was then cleared in xylene after which embedding in paraffin wax was carried out. Rotatory microtome was used to obtain tissue sections of 3-5 $\mu$ m thick. The sections were deparaffinised, hydrated and stained using haematoxylin and eosin (H\&E) dye. The sections were then mounted using neutral dibutylphthalate xylene (DPX) medium for microscopic examination at x40 magnification.

\subsection{Statistical analysis}

Data was analysed using Statistical Package for Social Sciences (SPSS) software (V20, USA). The results were presented as Mean \pm standard error of mean (SEM). One way Analysis of Variance (ANOVA) was used to determine the significance of difference in the means of all parameters. Dunnett post-hoc multiple comparison procedure was done for comparisons between treated groups and control. The results were considered statistically significant at $\mathrm{p}<0.05 \mathrm{level}$ of significance.

\section{Result and discussion}

The mean body weight change of the rats in Group B (Non-salted calabash chalk) which were administered $40 \mathrm{mg} / \mathrm{kg}$ body weight of the chalk suspension was significantly $(\mathrm{P}<0.05)$ lower when compared to the control Group A (Table 1$)$. The rats in group $C$ also showed reduction in body weight change, however, it was not significant $(\mathrm{P}>0.05)$ compared to the control group A. 
Table 1 Mean \pm SEM of initial body weight, final body weight and weight change in all the groups

\begin{tabular}{llll}
\hline Groups & Initial weight & Final weight & Weight change \\
\hline A & $203.64 \pm 11.58$ & $211.43 \pm 9.52$ & $7.79 \pm 4.56$ \\
B & $229.70 \pm 7.69$ & $208.39 \pm 14.54$ & $-46.46 \pm 23.60^{*}$ \\
C & $217.00 \pm 8.08$ & $212.02 \pm 8.06$ & $-4.98 \pm 2.73$ \\
F Ratio & 1.971 & 0.031 & 4.123 \\
Prob. of sig. & $0.182 \quad 0.969$ & 0.043 \\
\hline & & $*=P<0.05$ compared to control
\end{tabular}

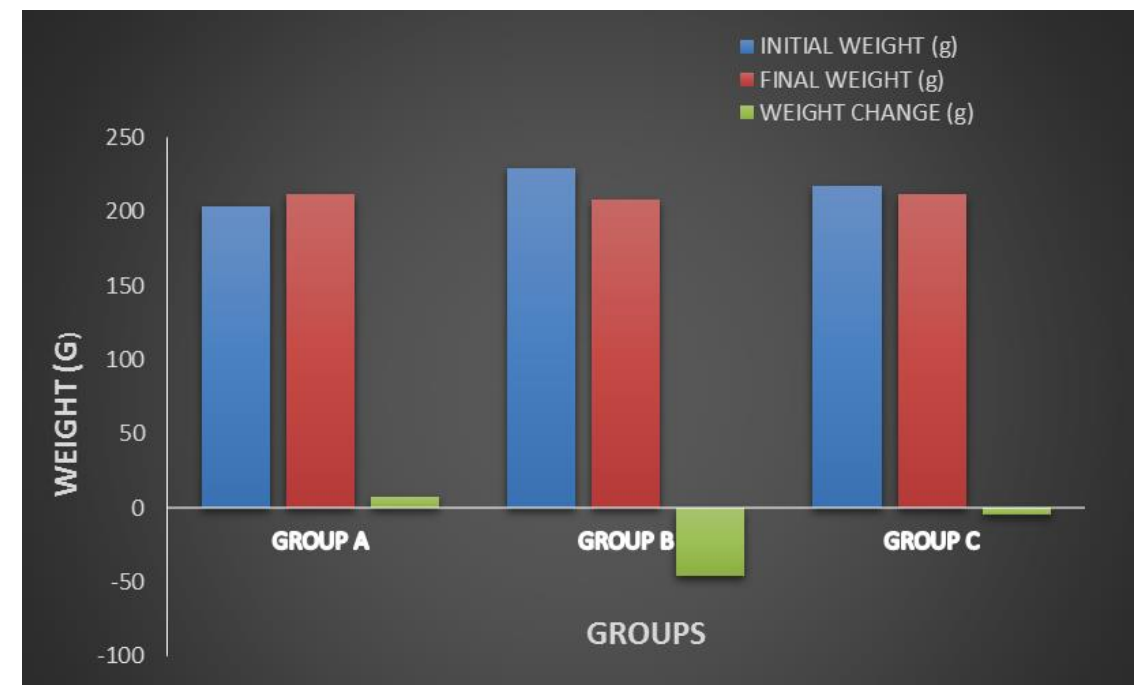

Figure 1 The body weight of all the groups

Photomicrograph sections of the uterus of animals in Group A (Figure 2) showed normal non-secreting uterine features with endometrium and myometrium. Group B (Figure 3) showed uterine tissue with endometrial hyperplasia and the presence of inflammatory cells, while Group C (Figure 4) showed uterine tissue with endometrial hyperplasia and epithelial metaplasia compared to the control group.

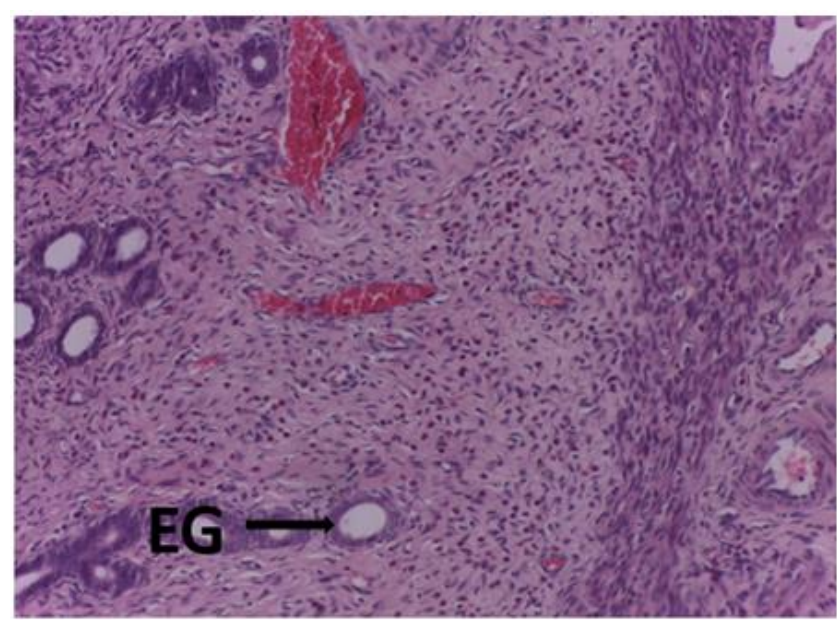

Figure 2 Photomicrograph section of the uterus of control group A (x40) (H/E) showing non-secreting endometrial gland (EG) 


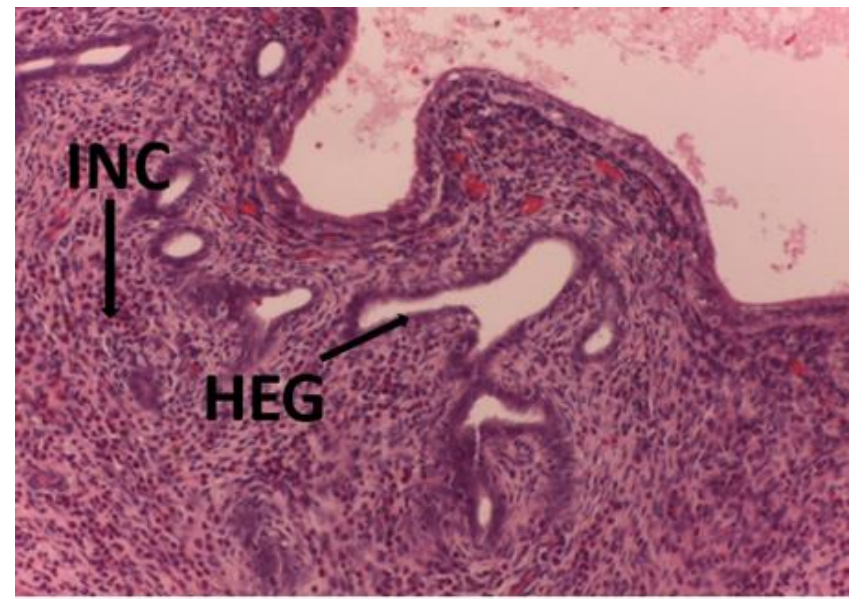

Figure 3 Photomicrograph section of the uterus of group B (x40) (H/E) treated with $40 \mathrm{mg} / \mathrm{kg}$ of non-salted calabash chalk showing hyperplastic endometrial gland (HEG) with presence of inflammatory cells (INC)

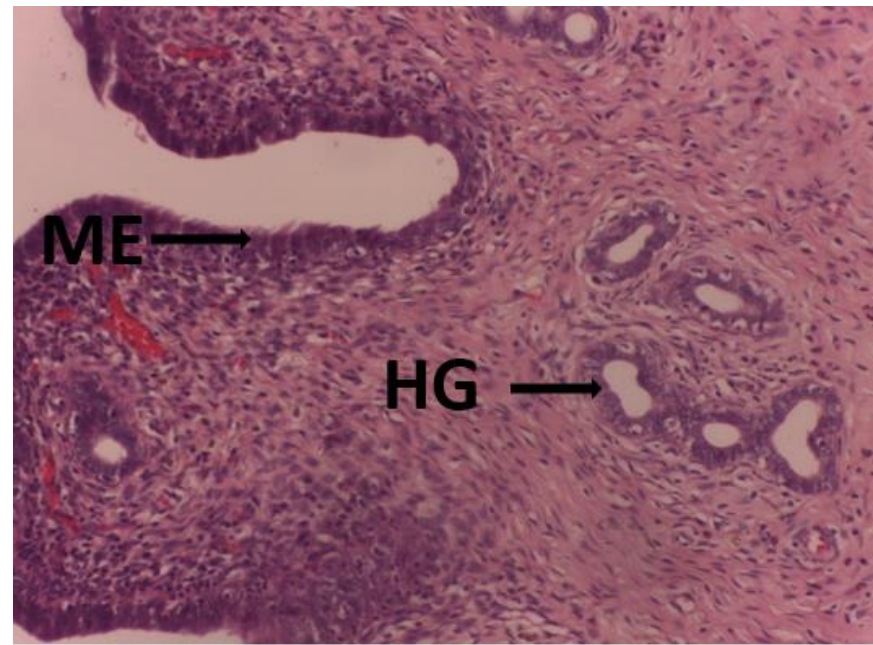

Figure 4 Photomicrograph section of the uterus of group C (x40) (H/E) treated with $40 \mathrm{mg} / \mathrm{kg}$ of salted calabash chalk showing metaplastic epithelium (ME) and hyperplastic gland (HG)

Calabash chalk has been reported to contain several adverse effects known to be detrimental to health. Pregnant and non-pregnant women have a predilection for consuming it especially in Nigeria and other sub-Saharan African countries [4]. Thus, this study evaluated the effects of calabash chalks (Salted and Non-salted) on the uterus of adult female Wistar rats.

The increase in body weight of animals in control group could be physiological as the animals were only exposed to water and feed throughout the experiment. The reduction in body weight could be due to the disruption in the absorption of nutrient by the chalk, since it contains Kaolin which has been reported to coat the lining of the gastrointestinal tract [7]. This coating prevents the absorption of beneficial nutrients which results to poor nutrition and loss of weight. This is in line with Oyewopo et al. [13] who reported a reduction in weight in the treated group when compared to control.

The histological changes observed in the uterus could be as a result of the presence of lead in calabash chalk. Metaplasia can lead to cancer if there are complications. This is in line with Nakade et al. [17] who reported the adverse effect of lead on the reproductive system (uterus) which caused chronic endometriosis with sloughing of the epithelial lining and severe vacuolar degeneration in the lining of endometrial cells. 


\section{Conclusion}

Calabash chalk showed histopathological changes in the uterus of the rats. This study has demonstrated the negative effects calabash chalk has on the uterus of adult female Wistar rats of which their tissues are similar to that of human. The findings of this study suggest that calabash chalk may alter growth rate and cause histological changes to the uterus and could be detrimental to the reproductive system and health. This research will help create awareness on the risks involved in the consumption of calabash chalk. Women especially of reproductive age should be discouraged from consuming this substance.

\section{Compliance with ethical standards}

\section{Acknowledgments}

We thank Dr. Ijioma Solomon for his technical support throughout the work.

\section{Disclosure of conflict of interest}

There was no conflict of interest in the research of this work

\section{Statement of ethical approval}

The experiment was carried out at Gregory University, Uturu with approval by the local ethics committee for animal care and use.

\section{References}

[1] Grigsby RK, Thyer BA, Waller RJ and Johnston GA. (1999). Chalk eating in middle Georgia: a culture-bound syndrome of pica. South Medical Journal, 92(2), 190-192.

[2] Popoola OE, Bisi-Johnson MA, Abiodun A and Ibeh OS. (2013). Heavy metal content and antimicrobial activities of some naturally occurring facial cosmetics in Nigeria. Ife Journal of Science, 15(3), 637-645.

[3] Ekong MB, Akpantah AO, Ibok OS, Eluwa MA and Ekanem TB. (2008). Differentia effect of calabash chalk on the histology of the liver of adult Wistar rats. The Internet Journal of Health, 8(2), 1-4.

[4] Dean JR, Deary ME, Gbefa BK and Scott WC. (2004). Characterization and analysis of persistent organic pollutants and major, minor and trace elements in Calabash chalk. Chemosphere, 57, 21-25.

[5] Halsted JA. (1968) Geophagia in man: Its nature and nutritional effects. Amplified Journal of Clinical Nutrition, 21(12), 1384-1393.

[6] Reilly C and Henry J. (2000). Geopaghia: Why do humans consume soil? Nutrition Bull., 25(2), 141-144.

[7] Abraham PW, Follansbee MA, Hunt A, Smith B and Wragg J. (2006). Iron nutrition and possible lead toxicity: an appraisal of geophagy undertaken by pregnant women of UK, Asian communities. Appl Geochem 21, 98-108.

[8] Ekong MB, John EE, Mbadugha CC, Bassey EI and Ekanem TB. (2012). Effects of calabash chalk on the histomorphology of the gastro-oesophageal tract of growing Wistar rats. The Malaysian Journal of Medical Sciences, 19(1), 30-35.

[9] Campbell H. (2002). Calabash chalk (Calabar stone, La Craie, Argile, Nzu, Mabele). Belfast: Chief Medical Officer, 4.

[10] European Union Commission regulation. (2001). Setting maximum level for certain contaminiants in food stuff (EC). Patent No. 466/2001.

[11] Canfield RL, Henderson junior CR, Cory-slechta DA, Cox C, Jusko TA and Lanphear BP. (2003). Intellectual impairment in children with blood lead concentrations below $10 \mu \mathrm{g}$ per deciliter. The New England Journal of Medicine, 348(16), 1517-1526.

[12] Shannon M. (2003). Severe lead poisoning in pregnancy. Ambulatory Pediatrics: the Official Journal of the Ambulatory Pediatric Association, 3(1), 37-39.

[13] Oyewopo AO, Obasi KK, Anumudu K and Yawson EO. (2017) Histological and hormonal studies of calabash chalk on ovarian function in adult female Wistar rats. J. Morphol Sci. 34(3), 173-177. 
[14] Ekong MB, Peter AI, Akpanabiatu M, Ekanem TB and Eluwa MA. (2013). Potency of calabash chalk on the liver function and histomorphology. Journal of Medical Research and Practice, 2(7), 202-207.

[15] Ekong MB, Ekanem TB, Sunday AO, Aquaisua AN and Akpanabiatu MI. (2012). Evaluation of calabash chalk effect on femur bone morphometry and mineralization in young Wistar rats: a pilot study. International Journal of Applied \& Basic Medical Research. 2(2), 107-110.

[16] Ekong MB, Ekanem TB, Abraham KE, Akpanabiatu MI, Peter AI and Edegha IA. (2009). Effects of calabash chalk on hematology indices and histomorphology of the spleen of growing Wistar rats. Instasci Journal of Medical Sciences and Clinical Research, 2(1), 1-7.

[17] Nakade PU, Garg KS, Sharma A, Choudhury S, Yadav SR, Gupta K and Sood N. (2015). Lead-induced adverse effect on the reproductive systemof rats with particular reference to histopathogical changes in uterus. Indian Journal of Pharmacology, 47(1), 22-26.

\section{How to cite this article}

Opara JK and Nwagbaraocha EC. (2018). The effect of calabash chalk on the uterus of adult female Wistar rats. GSC Biological and Pharmaceutical Sciences, 5(2), 26-31. 